Bio-grafía Escritos sobre la Biología y su Enseñanza.

Edición Extra-Ordinaria.

Memorias del I Congreso Nacional de Investigación en Enseñanza de la Biología. VI Encuentro Nacional de Investigación en Enseñanza de la Biología y la Educación Ambiental. ISSN 2027 1034. P. p. 243- 255.

\title{
LAS ARAÑAS COMO ORGANISMOS MODELO PARA CONOCER, COMPRENDER Y APRENDER SOBRE LAS INTERACCIONES BIOLOGICAS Y SABERES LOCALES.
}

SPIDERS AS MODEL ORGANISMS TO KNOW, UNDERSTAND AND LEARN ABOUT THE BIOLOGICAL INTERACTIONS AND LOCAL KNOWLEDGE.

\section{POR: Leydy Johanna Duarte Suarez ${ }^{1}$}

\section{RESUMEN.}

Este proyecto se está desarrollando en la Institución Educativa Agrícola de Macanal, Escuela Rural de San Pedro, surgió de la práctica pedagógica I, donde se realiza una contextualización de la Institución, zona y comunidad estudiantil, los pro y contra de la metodología utilizada en los procesos de enseñanza; planteando un proyecto para mejorar y aportar a la educación de la Institución, donde se promueve el aprendizaje significativo de los estudiantes. El proyecto "Las arañas como organismos modelo para conocer, comprender y aprender sobre las interacciones biológicas y saberes locales" se realiza con estudiantes de $0^{\circ}, 1^{\circ}$ y $4^{\circ}$ de primaria, porque la enseñanza de la biología debe partir desde la niñez, el primer acercamiento que tienen los niños es con el ambiente que los rodea, conocerlo y saber el por qué, cómo y para qué este está presente, es de gran importancia.

El objetivo principal de este proyecto es reconocer las interacciones biológicas en el entorno natural y los saberes locales, utilizando las arañas como organismos que permite generar estrategias didácticas. Los resultados evidencian el interés por parte de los niños en trabajar temáticas de biología; el desarrollo de habilidades conceptuales, procedimentales y actitudinales; y el reconocimiento y valoración del contexto tanto en lo biológico como lo cultural.

\section{ABSTRACT}

This project is being developed in the Educational Agricultural Institution Macanal Rural School of San Pedro. It emerged from the teaching practice I, a contextualization of the Institution, area and student community and the pros and cons of the methodology used in the teaching process were carried out; considering a project to improve and contribute to the education of the

${ }^{1}$ Estudiante de Licenciatura en Biología. Universidad Pedagógica Nacional. Centro Valle de Tenza.dbi07lduarte@gmail.com. 
Bio-grafía Escritos sobre la Biología y su Enseñanza.

Edición Extra-Ordinaria.

Memorias del I Congreso Nacional de Investigación en Enseñanza de la

Biología. VI Encuentro Nacional de Investigación en Enseñanza de la Biología

y la Educación Ambiental. ISSN 2027 1034. P. p. 243- 255.

institution, which promotes meaningful learning for students. The project "spiders as model organisms to know, understand and learn about biological interactions and local knowledge" was done with students at 0 , 1st, and 4th grade, because Biology teaching should start from childhood, the first approach that children have is with the surrounding environment, knowledge and know why, how and why it is present, it is of great importance.

The main objective of this project is to recognize the biological interactions in the natural environment and local knowledge, using spiders as organisms that allow to generate didactic strategies. The results demonstrate the children's interest in working Biology topics, the development of conceptual procedural and attitudinal skills and the recognition and appreciation of both the biological and cultural context .

Palabras clave: Arañas, interacción biológica, saberes locales y aprendizaje significativo.

Keywords: Spiders, biological interactions, local knowledge and meaningful learning.

\section{INTRODUCCION}

Desde el momento en que nacen los seres humanos, están rodeados por el entorno que les permite sobrevivir, proveyéndoles recursos necesarios para su subsistencia, como el alimento, el oxígeno, el agua, entre otros. En algunos casos como en los sectores rurales, este medio está más cercano y se está en contacto todo el tiempo con el; sin embargo algunas veces este espacio es visto solo como medio de producción o para obtener algún beneficio y son muy pocas las personas que lo valoran por la gran riqueza que posee.

A través del contacto directo con la naturaleza, del conocimiento que los niños de los sectores rurales tienen de esta, y de los mitos, creencias y leyendas que se tienen en la comunidad sobre las arañas, se pretende que los estudiantes conozcan la importancia del entorno más allá de lo que ven y vivencian cotidianamente. Es de gran importancia el reconocimiento del contexto y la valoración de este, porque a partir de estos es que los estudiantes pueden lograr un aprendizaje significativo.

"Los procesos de enseñanza y aprendizaje de la Biología deben estar fundamentados en la vida real/cotidiana, con el objetivo de hacer del proceso educativo algo más creativo, nuevo e interesante de resultados satisfactorios" (Medina, L. Vera, B. Bonilla \& G. Munares, L. 2009, p. 954); si se parte de las 
Bio-grafía Escritos sobre la Biología y su Enseñanza.

Edición Extra-Ordinaria.

Memorias del I Congreso Nacional de Investigación en Enseñanza de la

Biología. VI Encuentro Nacional de Investigación en Enseñanza de la Biología

y la Educación Ambiental. ISSN 2027 1034. P. p. 243- 255.

vivencias de los estudiantes y de las realidades del contexto, es de mayor facilidad generar un aprendizaje significativo en los niños.

El orden araneae, es un grupo que ayudará a descubrir, comprender y valorar, por un lado, la importancia de un organismo en un ecosistema, por las interacciones biológicas que se presentan, ya que este grupo cumple funciones importantes en la regulación de las cadenas alimenticias, tanto por su función como presa y también como depredador, y por otro lado, descubrir y aprender de los conocimientos culturales de la comunidad de la vereda Muceño del municipio de Macanal que se tienen a cerca de estos organismos.

"Las arañas son un grupo grande, distintivo y extendido; estas ocurren en muchos tipos de hábitats siendo a menudo muy abundantes. Muchas personas tienen la idea de que las arañas son muy venenosas, y aunque casi todas tienen glándulas venenosas, estas raras veces muerden al ser humano; únicamente pocas especies tienen venenos peligrosos" (Borror, D., De Long, D. \& Triplehorn, 1981), conocer la biología de las arañas que se encuentran en la zona verde de la escuela, y en los alrededores, permiten una mejor comprensión, valoración y reconocimiento del entorno.

Se han realizado varios trabajos en Instituciones educativas, que incluyen diferentes seres vivos, utilizándolos como estrategias 0 herramientas pedagógicas para el desarrollo de habilidades investigativas y la construcción de conocimientos.

Dentro de estos cabe destacar: "Modelos mentales al interrelacionar los conceptos de célula y ecosistema, utilizando a los insectos como eje transversal" (Medina, L., Vera, B., Bonilla, G \& Munares, L. 2009), el trabajo presenta una investigación cualitativa, estudio de casos comparativo, descriptiva con observación participativa, los resultados muestran que los estudiantes presentaron modelos innatos, económicos, finitos y de identidad estructural. Los insectos son un material potencialmente significativo, porque permitieron adquirir un progreso conceptual en los estudiantes. En conclusión, los insectos permiten desarrollar actividades llamativas y divertidas, facilitando la interrelación entre temáticas, el diálogo entre diferentes disciplinas del saber y fundamentalmente, acercándonos aún más a un conocimiento significativo.

Otro trabajo de gran relevancia es "La colección de microalgas de la Universidad Pedagógica Nacional como estrategia didáctica para la enseñanza y aprendizaje de conceptos biológicos" (Delgadillo, I., Góngora, F. \& Medellín, F. 2009), donde se resalta la importancia de la utilización de la colección de microalgas para fortalecer y aumentar la calidad de los procesos educativos, basándose en el principio didáctico que indica que "se aprende más a través de la participación activa, enfocándose el interés en aprender haciendo" (Segura, 2000). Para la reestructuración de la Ficoteca de la Universidad Pedagógica Nacional, se elaboraron materiales educativos que transforman la colección en 
Bio-grafía Escritos sobre la Biología y su Enseñanza.

Edición Extra-Ordinaria.

Memorias del I Congreso Nacional de Investigación en Enseñanza de la

Biología. VI Encuentro Nacional de Investigación en Enseñanza de la Biología

y la Educación Ambiental. ISSN 2027 1034. P. p. 243- 255.

una estrategia didáctica, que al ser utilizada en el aula de clase permite que los alumnos aprendan por su propia experiencia, encaminándose en el descubrimiento de las ideas; como explica Segura (2000), "no constituye un medio para facilitar la enseñanza, sino que es la enseñanza misma, ya que manipular es aprender".

Como los trabajos anteriores hay varios, que le apuestan a la utilización de diferentes organismos como estrategias para la enseñanza de la biología. Pero las arañas han sido un grupo de organismos marginados o poco trabajados en las estrategias educativas.

\section{METODOLOGÍA.}

El desarrollo de este trabajo se realiza con investigación cualitativa, utilizando el método de investigación-acción, este implica un talante democrático en el modo de hacer investigación, una perspectiva comunitaria. No se puede realizar de forma aislada; es necesaria la implicación grupal. Se considera fundamental la toma de decisiones de forma conjunta, orientada hacia la creación de comunidades autocriticas con el objetivo de transformar el medio social.

Este proyecto genera habilidades de indagación, observación, descripción, explicación, reflexión, imaginación y experimentación, del contexto natural y cultural que permitirán en el estudiante el aprendizaje significativo de las interacciones biológicas y saberes locales, a partir del trabajo colectivo y comunitario.

- FASE I: Elaboración de Diario de campo.

Se han elaborado Diarios de Campo con materiales reciclables con el fin de generar aprendizajes sobre la generación de registros propios de salidas de campo en los niños de la escuela. . La forma del registro de la información fue: los estudiantes de grado cero dibujaron; los de primero dibujaron y una parte escrita; los de cuarto de primaria escrito y dibujado.

- FASE II: Reconocer aspectos morfológicos de las arañas que se encuentran en la escuela y alrededores. Para ello se realizaron salidas de campo y un laboratorio que se describen a continuación

Salida de Campo I: Se realizó una salida de campo, para agudizar los sentidos de los estudiantes, con el fin de conocer a las arañas según su hábito (tejedoras, cazadoras) y las estrategias que estas utilizan para poder sobrevivir, los cuidados que se deben tener cuando se trabaja con estos organismos y la forma de manipulación. En esta salida se hizo un recorrido por las zonas 
Bio-grafía Escritos sobre la Biología y su Enseñanza.

Edición Extra-Ordinaria.

Memorias del I Congreso Nacional de Investigación en Enseñanza de la

Biología. VI Encuentro Nacional de Investigación en Enseñanza de la Biología

y la Educación Ambiental. ISSN 2027 1034. P. p. 243- 255.

verdes de la escuela y por los alrededores de esta, dependiendo del interés de los estudiantes por las arañas tejedoras o cazadoras, se realizan grupos o si el interés general es por los dos tipos de arañas, entonces se trabajan entre todos los estudiantes.

Salida de Campo II: Esta se realizó con el fin de conocer la diversidad de arañas que se encuentra en la escuela y alrededores. Tomando un espécimen de cada tipo de arañas que los estudiantes consideren diferente, y contando el número de organismos que se encuentren de este tipo.

Laboratorio I: Para este primer laboratorio se uso un estereoscopio que permitió identificar la morfología de las arañas (espirinetes, pedipalpos, quelíceros, ocelos, prosoma, opistosoma), y la función de cada una de sus partes, para ello se tomaron dos arañas cazadoras.

También se trabajó la diferencia entre arañas e insectos dado que las arañas son confundidas muchas veces con los insectos, se trabajó con una avispa y hormigas.

Se trabajó con la nominación que establecieron los estudiantes inicialmente para las partes, comparándolos con los términos científicos.

> FASE III: Observación del ciclo de vida de las arañas, a través de la elaboración de terrarios.

Los niños (as) realizaron la adecuación de terrarios para las arañas, cada estudiante eligió una araña para cuidarla, y se le colocó un número al espécimen.

\section{Laboratorio II:}

- Para una mejor comprensión de la reproducción de las arañas, se realizó un laboratorio donde se observaron los órganos utilizados en la reproducción.

> FASE IV: Identificar las interacciones de las arañas con el ambiente físico y con otros organismos.

Video: Proyección de una película sobre arañas, con el fin de reconocer la importancia de estos organismos, y mostrar un panorama general de las interacciones de las arañas con el medio y con otros organismos. En esta clase también se trabaja la forma de fabricación de la tela, producto de gran importancia para la supervivencia de la mayoría de arañas. 
Bio-grafía Escritos sobre la Biología y su Enseñanza.

Edición Extra-Ordinaria.

Memorias del I Congreso Nacional de Investigación en Enseñanza de la

Biología. VI Encuentro Nacional de Investigación en Enseñanza de la Biología

y la Educación Ambiental. ISSN 2027 1034. P. p. 243- 255.

Salida de Campo III: Esta salida se realizó con el fin de que los estudiantes conocieran la importancia que ejercen las arañas en los ecosistemas, las interacciones de estas con el medio y sus funciones como presa o como depredador, y la forma en que estas se alimentan. En esta salida se evidenciaron los métodos que utilizan las arañas para obtener el alimento, dependiendo de su forma de vida (tejedoras o cazadoras).

> FASE V: Reconocer los saberes locales que tienen los estudiantes y la comunidad sobre las arañas.

Salida de Campo IV: Indagación de las creencias que las personas tienen frente a este tipo de organismos (mitos o leyendas), para esto los estudiantes y el guía hablan con algunas personas de la comunidad que puedan y quieran dialogar sobre el tema. En esta salida los estudiantes ejercen el papel de entrevistadores; anterior a esto se ha tenido una preparación en clase de lo que se quiere indagar y lo que los estudiantes quieren preguntar.

Salida de Campo V: Realizada con el fin de visitar a algunas personas de la comunidad y escucharlas sobre lo que saben de las arañas su reproducción, alimentación, regulación de los ecosistemas, y si estos organismos tienen algún tipo de importancia para ellos.

\section{RESULTADOS.}

Los resultados son parciales, ya que algunas fases están en desarrollo.

FASE I: (Imágenes 1, 2 y 3).La construcción del diario de campo se realizó con cartón, hojas de cuaderno y lana, utilizando el cartón como pasta del diario, las hojas en medio de la pasta y la lana para unir las hojas. Luego cada estudiante decoro una cara del cartón, que sería utilizada como la pasta principal del diario. En esta actividad los estudiantes estuvieron muy motivados, mostrando una actitud positiva, expresión de alegría y emoción por lo que se estaba realizando. La descripción de los diarios de campo, es acorde al grado en el que se encuentran.

Los diarios de campo permiten conocer los avances que han tenido los estudiantes en cuanto al tema de las arañas, pues allí se describen las actividades realizadas y se puede observar dibujos y escritos realizados por los estudiantes, plasmando lo aprendido.

FASE II, durante la primera Salida los estudiantes mostraron un gran interés por los organismos con los que se estaba trabajando, se les facilita la observación y manipulación de estos organismos sin causarles daño. Se generaron tanto habilidades procedimentales como actitudinales. El interés de los estudiantes fue por las arañas cazadoras. 
Bio-grafía Escritos sobre la Biología y su Enseñanza.

Edición Extra-Ordinaria.

Memorias del I Congreso Nacional de Investigación en Enseñanza de la

Biología. VI Encuentro Nacional de Investigación en Enseñanza de la Biología

y la Educación Ambiental. ISSN 2027 1034. P. p. 243- 255.

Salida II: (Imágenes 4, 5 y 6). Diversidad de arañas: los niños (as) llevaron tarros con el fin de colocar arañas de especies diferentes en cada uno, para luego contar los individuos de cada especie y el número que se encontraron (Tabla $N^{\circ} 1$ ), esta salida fue realizada a los alrededores de la Institución. En total se observaron 8 especies diferentes. Se explicó el termino diversidad, analizando la cantidad de arañas que se presentaban y el por qué un número de individuos diferente para cada especie. Al finalizar la clase las arañas capturadas fueron liberadas.

Tabla 1: Diversidad de arañas en los alrededores de la escuela.

\begin{tabular}{|c|c|}
\hline Espécimen. & № de individuos \\
\hline Sp 1. & 3 \\
\hline Sp 2. & 6 \\
\hline Sp 3. & 2 \\
\hline Sp 4. & 4 \\
\hline Sp 5. & 4 \\
\hline Sp 6. & 8 \\
\hline Sp 7. & 5 \\
\hline Sp 8 & + de 30. \\
\hline
\end{tabular}

A continuación se muestra textos de estudiantes, escritos en el diario de campo:

"Hoy salimos con Leydy a capturar arañas de diferentes especies y yo capture un macho $y$ tiene ocho patas $y$ en sus patas tiene como chusitos, $y$ encontramos muchísimas diferentes y yo tenía un macho y las describimos y nos fuimos y a una de Brayan le ganaba lo de atrás" Daniel Barreto. Estudiante de $4^{\circ}$.

"Mi araña es tejedora, se estaba comiendo un mosco, la echamos al tarro y después la soltamos" Pedro Barreto. Estudiante de $1 \stackrel{0}{.}$

Laboratorio I: (Imágenes 7, 8 y 9)

La observación de arañas a través del estereoscopio, permitió conocer la morfología de las arañas. Los niños estaban muy interesados en realizar la observación, dibujaron en el diario de campo lo que observaban en este laboratorio (Imágenes 10, 11, 12 y 13). Luego se observaron insectos (avispa) con el fin de conocer las diferencias entre las arañas e insectos. Ellos nombran a las diferentes partes de la araña de la siguiente forma: Ponzoñas (quelíceros), ocelos (ojos) cabeza (cefalotórax) y cuerpo (abdomen), comparándolos a su vez con los términos científicos, se explicó la función de cada parte y se aclararon algunas dudas. 
Bio-grafía Escritos sobre la Biología y su Enseñanza.

Edición Extra-Ordinaria.

Memorias del I Congreso Nacional de Investigación en Enseñanza de la

Biología. VI Encuentro Nacional de Investigación en Enseñanza de la Biología

y la Educación Ambiental. ISSN 2027 1034. P. p. 243- 255.

A continuación se muestra textos de estudiantes, escritos en el diario de campo, el día que se realizó el laboratorio:

“La araña que atraparon los niños tenía cuatro patas en cada lado y tenía ponzoñas y pedipalpos y no le pudimos ver las ponzoñas y Leydy trajo el estereoscopio y vimos una araña y son muy peludas y la dibujamos, y le miramos la cosita donde botan la seda" Daniel Barreto. Estudiante de 4ํ․

\section{FASE III:}

Construcción de terrarios: (Imágenes 14, 15 y 16). Esta actividad fue tal vez una de las más exitosas, pues los estudiantes se divirtieron en la realización de esta, promoviendo el aprendizaje significativo a partir de la realidad.

A cada araña colocada en los terrarios, los estudiantes le están realizando seguimiento, escribiendo en su diario de campo si la araña presenta cambios. Están pendientes de su alimentación y de lo que este organismo necesita (Imágenes 17, 18 y 19). A continuación se presentan algunos escritos realizados por los estudiantes en su diario de campo:

"Leydy palio, salió mucha tierra y hecho en cada tarro la tierra, luego le echamos pasto, luego le mostramos a Leydy y vimos un árbol y había muchas arañas. Encontramos muchas arañas" Diana Barreto. Estudiante de 1ํ․

"Mi araña tiene pedipalpos son los que sienten las presas y es cazadora y corre arto y come bichos". Pedro Barreto. Estudiante de $1^{\circ}$.

"Hoy hicimos los terrarios y yo conseguí un araña con huevo y Leydy dice que son delicadas en ese estado. Mi araña es veloz y tiene cuatro ojos y cuatro patas en cada lado, tiene ponzoñas con la que inyecta el veneno y tiene pedipalpos para sentir los enemigos o sus presas" Daniel Barreto. Estudiante de $4^{\circ}$.

A partir de la construcción de terrarios y el seguimiento, que los estudiantes están realizando a estos organismos se explica el ciclo de vida de las arañas.

- Reproducción de las arañas.

- Arañas ovíparas.

- Arañas poco gregarias.

- Mudas de piel de las arañas antes de ser adultas.

- Aberturas genitales del macho y la hembra. 
Bio-grafía Escritos sobre la Biología y su Enseñanza.

Edición Extra-Ordinaria.

Memorias del I Congreso Nacional de Investigación en Enseñanza de la

Biología. VI Encuentro Nacional de Investigación en Enseñanza de la Biología y la Educación Ambiental. ISSN 2027 1034. P. p. 243- 255.

FASE IV:

Salida V: Las actividades preparadas para esta salida se han realizado en las diferentes sesiones, pues es necesario, aclarar las dudas de los estudiantes y explicar la importancia de las arañas en los ecosistemas, las interacciones de estas con el medio y sus funciones como presa o como depredador, y la forma en que estas se alimentan. En las actividades realizadas, a los estudiantes le surgía inquietudes, sobre los temas mencionados anteriormente y se iban desarrollando las temáticas planteadas para esta salida.

\section{DISCUSION.}

Las clases de Ciencias Naturales desarrolladas en Escuela Nueva es a partir de cartillas, estas plantean actividades que algunas veces son descontextualizadas, impidiendo que los estudiantes reconozcan su contexto y logren aprendizaje significativo. El proyecto "Las arañas como organismos modelo para conocer, comprender y aprender sobre las interacciones biológicas y saberes locales", atraen el interés de los estudiantes, pues se trabaja con organismos del entorno, utilizando metodologías diferentes a las tradicionales, permitiendo un aprendizaje significativo.

Se han encontrado varios trabajos realizados en Instituciones educativas, que incluyen diferentes seres vivos, tales como "Modelos mentales al interrelacionar los conceptos de célula y ecosistema, utilizando a los insectos como eje transversal" (Medina, L. Vera, B. Bonilla \& G. Munares, L. 2009); "La colección de microalgas de la Universidad Pedagógica Nacional como estrategia didáctica para la enseñanza y aprendizaje de conceptos biológicos" (Delgadillo, I., Góngora, F. \& Medellín, F. 2009); "Propuesta para el aprendizaje del tema de biodiversidad a través del método por descubrimiento, mediante la compilación de notas científicas sobre insectos" (Santana, A., Olvera, H., Cárdenas, L., \& Rivero, J.); "Insectos como herramienta de enseñanza en Educacion primeria y segundaria" (Matthews, R., Flage, L., \& Matthews, J.1997).

En los trabajos mencionados se utilizan los organismos como estrategias o didácticas para generar el aprendizaje significativo 0 el desarrollo de habilidades investigativas, estos trabajos muestran la importancia de trabajar con seres vivos, como estrategias que mejoran las metodologías educativas. Pero las arañas han sido un grupo de organismos marginados o poco trabajados en el aula, esta oportunidad permite reconocer el maravilloso mundo de las arañas, y a su vez genera en los estudiantes el desarrollo de habilidades conceptuales, procedimentales y actitudinales. 
Bio-grafía Escritos sobre la Biología y su Enseñanza.

Edición Extra-Ordinaria.

Memorias del I Congreso Nacional de Investigación en Enseñanza de la

Biología. VI Encuentro Nacional de Investigación en Enseñanza de la Biología

y la Educación Ambiental. ISSN 2027 1034. P. p. 243- 255.

Las conceptuales con términos y conceptos biológicos y culturales permitiendo que los estudiantes se apropien de conceptos y temáticas tales como ecosistema, poblaciones, especies, ciclo de vida, morfología, diversidad biológica, saberes locales, mitos, creencias, entre otros; dentro de las actitudinales encontramos indagación, observación, descripción, explicación, reflexión, imaginación y experimentación; y las procedimentales se fueron mejorando en cada una de las actividades realizadas.

El desarrollo de este proyecto permite que los estudiantes construyan conocimiento a partir de lo que saben y conocen, la facilidad con la que los niños realizan el trabajo con organismos del entorno es admirable.

La realización de un trabajo con arañas, genera en los estudiantes un mayor respeto por los diferentes seres vivos y los incentiva al reconocimiento y valoración de estos y de los saberes cotidianos que tienen las personas de la comunidad, teniendo en cuenta el contexto y aprovechándolo para la enseñanza.

Los saberes locales, se deben integrar en la enseñanza de la biología pues es de gran importancia conocer lo pensamientos y las creencias de la comunidad acerca de los diferentes organismos. Las estrategias educativas para la enseñanza de la biología deben tener en cuenta el contexto cultural y ambiental.

\section{CONCLUSIONES.}

> Las arañas son un grupo de organismos adecuados para aprender acerca de las interacciones biológicas y conocer los saberes locales porque despiertan el interés de los estudiantes, y se prestan para involucrar el contexto biológico y cultural.

$>$ Involucrar a la comunidad en los procesos educativos, permite que los estudiantes valoren los saberes de las personas de la región.

$>$ El proyecto de arañas es una estrategia que logra un aprendizaje significativo en los estudiantes, ya que permiten la realización de diferentes actividades, promoviendo el desarrollo de habilidades investigativas.

$>$ El reconocimiento del contexto es la mejor alternativa para desarrollar los procesos de enseñanza, porque a partir del conocimiento que los estudiantes poseen, se continúa un proceso de construcción de conocimiento. 
Bio-grafía Escritos sobre la Biología y su Enseñanza.

Edición Extra-Ordinaria.

Memorias del 1 Congreso Nacional de Investigación en Enseñanza de la Biología. VI Encuentro Nacional de Investigación en Enseñanza de la Biología y la Educación Ambiental. ISSN 2027 1034. P. p. 243- 255.

$>$ En la Educación Rural este tipo de proyectos son de gran importancia porque permite a los estudiantes una mejor comprensión y valoración de su contexto natural y cultural.

\section{BIBLIOGRAFIA}

- Almada, M. \& Medrano, C. (2006). Guía Didáctica De Arañas. Museo Provincial de Ciencias Naturales "Florentino Ameghino".

- Arango, N., Chaves, M., E., \& Feinsinger, P. (2002). Enseñanza de ecología en el patio de la escuela. National Audubon Society

- Borror. D; De Long, D \& Triplehorn, C. (1981). An introduction to study of Insects, fifth. College Publishing. USA.

- De Zubiría S, Miguel. (2004). Enfoques Pedagógicos y Didácticas contemporáneas. Editorial Fundación internacional de Pedagogía conceptual.

- Delgadillo, I., Góngora, F. \& Medellín, F. (2009) La colección de microalgas de la Universidad Pedagógica Nacional como estrategia didáctica para la enseñanza y aprendizaje de conceptos biológicos. Tecné, episteme y Didaxis. (TED No. Extraordinario,) $4^{\circ}$ Congreso Internacional sobre Formación de Profesores de Ciencias.

- Matthews, R., Flage, L., \& Matthews, J.(1997). Insects as Teaching Tools in primary and secondary education. Department of Entomology, the University of Georgia, Athens.

- Medina Gallego, C. (2007). ¿Cómo se hace una clase? Didáctica de lo posible. Editorial Universidad Nacional de Colombia.

- Medina, L. Vera, B. Bonilla, G. Munares, L. (2009). Modelos mentales al interrelacionar los conceptos de célula y ecosistema, utilizando a los insectos como eje transversal. Tecné, episteme y Didaxis. (TED No. Extraordinario,) $4^{\circ}$ Congreso Internacional sobre Formación de Profesores de Ciencias.

- Pozo, J. I.; Crespo, M.A. (2006). Aprender y enseñar ciencia. Ediciones Morata S.L.

- Rico, A., Beltrán, J., Álvarez, A. \& Flórez E. (2005). Diversidad De Arañas (Arachnida: Araneae) En El Parque Nacional Natural Isla 
Memorias del I Congreso Nacional de Investigación en Enseñanza de la Biología. VI Encuentro Nacional de Investigación en Enseñanza de la Biología y la Educación Ambiental. ISSN 2027 1034. P. p. 243- 255.

Gorgona, Pacífico Colombiano. Instituto de Ciencias Naturales, Universidad Nacional de Colombia. A.A. 7495, Bogotá, Colombia.

- Santana, A., Olvera, H., Cárdenas, L., \& Rivero, J. (2008)Propuesta para el aprendizaje del tema de biodiversidad a través del método por descubrimiento, mediante la compilación de notas científicas sobre insectos. XVI Congreso Nacional de Divulgación de la Ciencia y la Técnica

\section{ANEXOS.}

\section{IMÁGENES.}
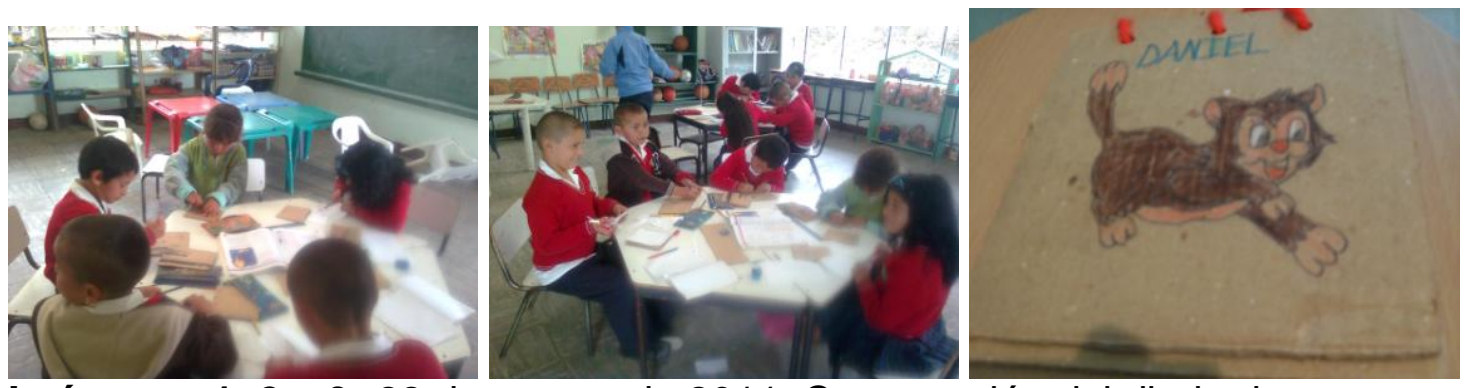

Imágenes 1, 2 y 3: 22 de agosto de 2011. Construcción del diario de campo.
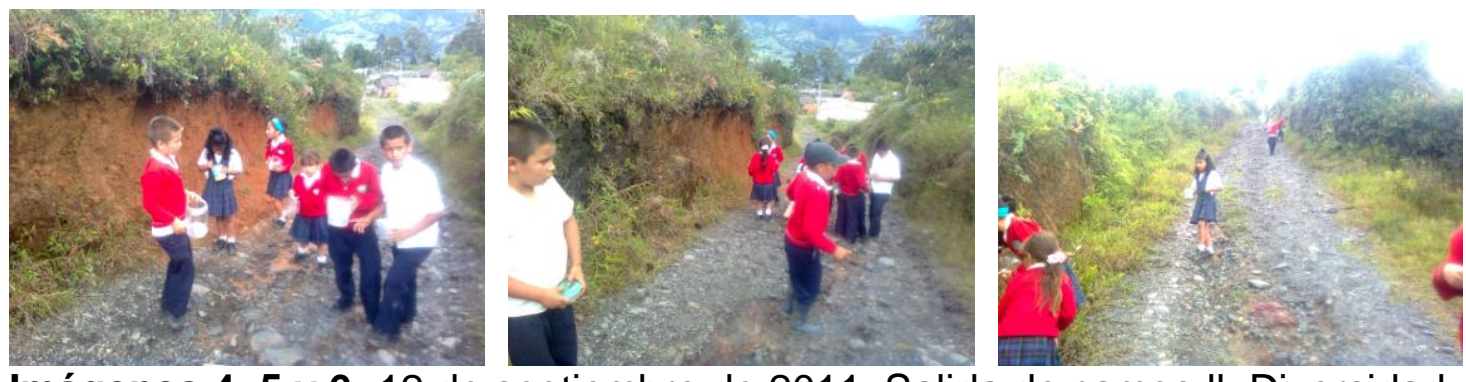

Imágenes 4, 5 y 6: 12 de septiembre de 2011. Salida de campo II. Diversidad de arañas.
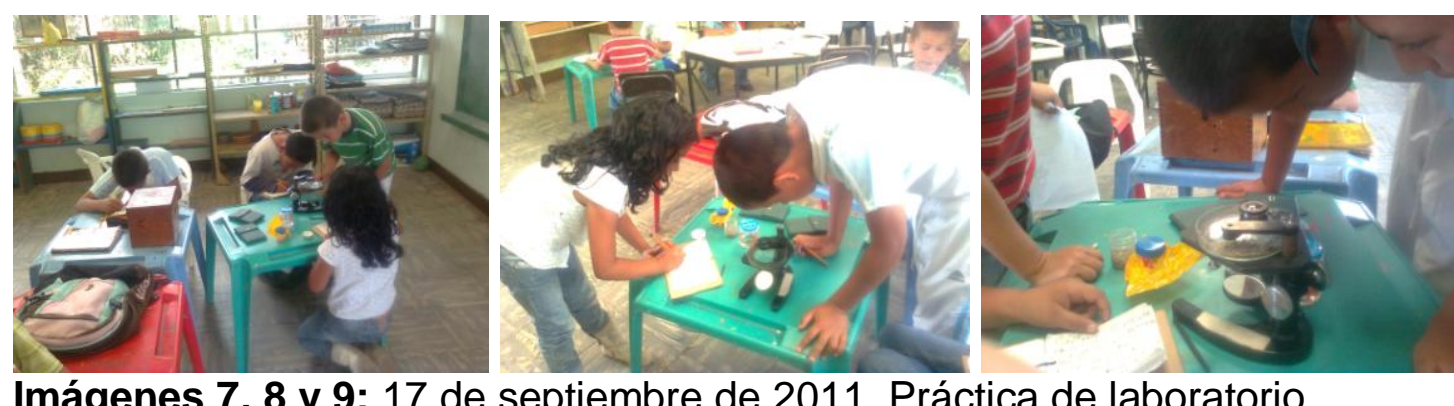

Imágenes 7, 8 y 9: 17 de septiembre de 2011. Práctica de laboratorio.

(1) 
Bio-grafía Escritos sobre la Biología y su Enseñanza.

Edición Extra-Ordinaria.

Memorias del I Congreso Nacional de Investigación en Enseñanza de la Biología. VI Encuentro Nacional de Investigación en Enseñanza de la Biología y la Educación Ambiental. ISSN 2027 1034. P. P. 243- 255.
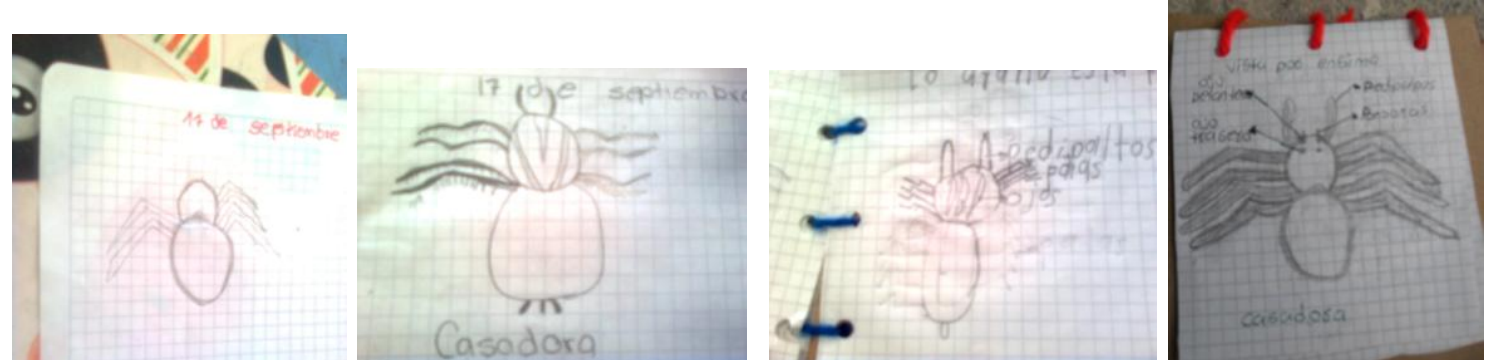

Imágenes 10, 11, 12 y 13: 17 septiembre de 2011. Dibujos de los estudiantes del laboratorio
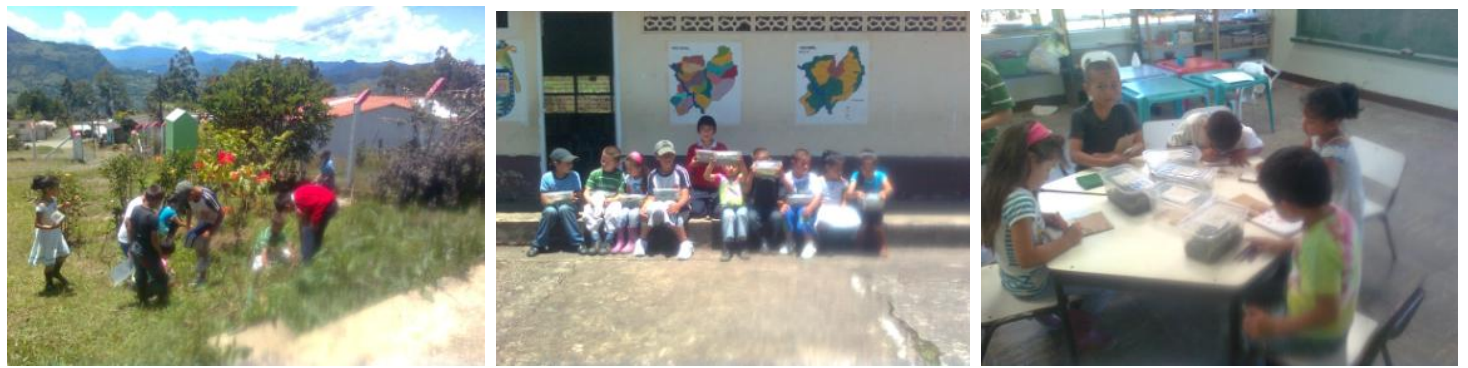

Imágenes 14, 15 y 16: 27 de agosto de 2011. Construcción de terrarios.
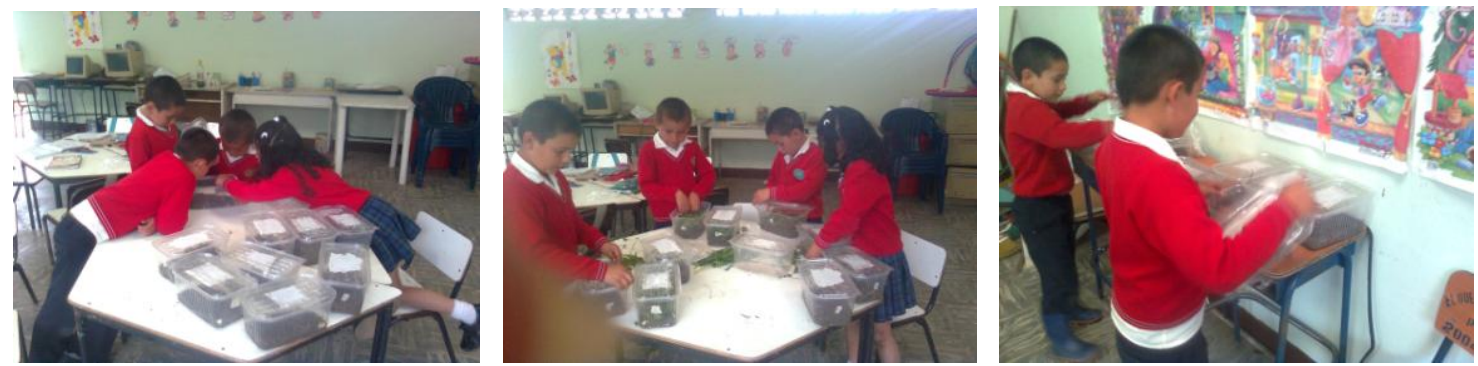

Imágenes 17, 18 y 19: Seguimiento a las arañas. 